\section{MORBIDITY POST SURGICAL PATENT DUCTUS ARTERIOSUS LIGATION IN VERY LOW BIRTH WEIGHT INFANTS (VLBW)}

P.J. Shukla ${ }^{1}$, A. El-Khuffash ${ }^{2}$, L. Nolke ${ }^{3}$, K. Walsh ${ }^{4}$, E.J. Molloy ${ }^{1,2,5}$

${ }^{1}$ UCD School of Medicine and Medical Sciences, University College Dublin, Belfield, ${ }^{2}$ Department of Neonatology, National Maternity Hospital, ${ }^{3}$ Department of Paediatric Cardiothoracic Surgery, ${ }^{4}$ Department of Paediatric Cardiology, Our Lady's Hospital for Sick Children, ${ }^{5}$ Royal College of

Surgeons of Ireland, Dublin, Ireland

Background: PDA ligation in premature infants has low surgical morbidity but substantial late mortality and high incidence of morbidity in the survivors. Recently, PDA ligation has been associated with poorer neurosensory outcomes compared with medical treatment alone. In addition the systemic inflammatory response associated with surgery has been postulated to contribute to poor neurodevelopmental outcomes.

Aim: To identify and evaluate the presence of morbidities following surgical ligation of PDA

Methods: Infants who had a surgical PDA ligation in Ireland over 6 years were included in this study if birth weight $<1500 \mathrm{~g}$ or $<32$ weeks gestation. Exclusions were made on the basis of concomitant severe congenital abnormalities. We included Vermont Oxford Network data outcomes from infants born in Dublin.

Results: $132(35 \%)$ infants were included in the study having a mean gestational age of 26.5 (range: 23-32.2) weeks, birth weight 882 (range: $440-1470$ g) and male infants numbered seventy $(53 \%)$. Within the cohort, 77 infants were referred for surgical ligation from Dublin maternity hospitals and followup data was available for 73 infants: $15(20 \%)$ developed NEC with 7(9\%) undergoing further surgery for NEC, 24\% required laser for ROP, 69 had RDS, 8 had pneumothorax, GI Perforation was noted in 3 infants, and a bacterial pathogen was isolated in 10 infants. Baseline inflammatory indices were also significantly altered postoperatively with reduced Alb, PIts, monocytes and lymphocytes.

Conclusion: Infants undergoing PDA ligation have an increased percentage of RDS, NEC, pneumothorax, and GI perforation, although ROP is lower than the Vermont Oxford Network data.

\section{URINARY MARKERS FOR ACUTE TUBULAR INJURY FOLLOWING PAEDIATRIC CARDIOPULMONARY BYPASS}

\section{A.J. Alcaraz Romero', G. Tesorero Carcedo',}

J. Urbano Villaescusa ${ }^{1}$, M. Botrán Prieto',

C. Romero Román², A. García Figueruelo', R. González Cortés ${ }^{1}$

\section{${ }^{1}$ Servicio de Cuidados Intensivos Pediátricos, \\ ${ }^{2}$ Servicio de Bioquímica, Hospital General \\ Universitario Gregorio Marañon, Madrid, Spain}

Background and aims: Cardiopulmonary bypass (CPB) has proved to alter organs functions. The aim of this study was to evaluate the reliability of urinary biomarkers when diagnosing acute kidney injury (AKI) after CBP.

Methods: Prospective, observational study. Paediatric patients who underwent CPB were included during a 4 month period. Surgical aggression was related to aortic cross-clamp (ACC), circulatory arrest, severe hypothermia and CPB duration. Postoperative AKI was based on serum creatinine $(\mathrm{Cr})$ elevation by $50 \%$ from baseline or need of dialysis. Cystatin $\mathrm{C}(\mathrm{CyC}), \mathrm{N}$-acetylb-glucosaminidase (NAG) and a1-microglobulin (a1mg) urinary values and plasmatic CyC were analysed using fractional excretion of $\mathrm{CyC}$ ( $\mathrm{FEcC}$ ), $\mathrm{NAG} / \mathrm{Cr}$ ratio (normal $15 \mathrm{U} / \mathrm{g} \mathrm{Cr}$ ) and $\mathrm{a} 1 \mathrm{mg} / \mathrm{Cr}$ ratio (normal $0.1-14 \mathrm{mg} / \mathrm{g} \mathrm{Cr}$ ). Data presented as median (P25-P75).

Results: 31 patients were included. Median age was 10 months (4-78 months). 11 children presented postoperative AKI. 29 patients showed increased excretion of NAG, median 51.0 (23.8$73.8 \mathrm{UI} / \mathrm{g} \mathrm{Cr})$. a $1 \mathrm{mg} / \mathrm{cr}$ values were elevated in all children, median 172.9 (70.6-392.9 mg/g Cr). a1mg and FEcc values were higher amongst children presenting AKI $(0.14 \%, 330 \mathrm{mg} / \mathrm{g}$ Cr vs $0.06 \%, 96$ $\mathrm{mg} / \mathrm{g} \mathrm{Cr}, P<0.02)$. In this group CPB duration and ACC time were also higher $(215,108$ vs 156,77 minutes, $P<0.03)$. Correlation between FEcc and a $1 \mathrm{mg} / \mathrm{cr}$ as well as between both FEcc and $a 1 \mathrm{mg} /$ $\mathrm{cr}$ and ACC time was found.

Conclusions: Tubular injury is frequent amongst children undergoing CBP. Magnitude of surgical aggressions might influence postoperative AKI. FEcc and $a 1 \mathrm{mg} / \mathrm{cr}$ could be of use when analysing AKI after CBP. 